NASA/TM-2001-210711

Density Fluctuation in Asymmetric Nozzle Plumes and Correlation With Far Field Noise

\author{
J. Panda \\ Ohio Aerospace Institute, Brook Park, Ohio \\ K.B.M.Q. Zaman \\ Glenn Research Center, Cleveland, Ohio
}


Since its founding, NASA has been dedicated to the advancement of aeronautics and space science. The NASA Scientific and Technical Information (STI) Program Office plays a key part in helping NASA maintain this important role.

The NASA STI Program Office is operated by Langley Research Center, the Lead Center for NASA's scientific and technical information. The NASA STI Program Office provides access to the NASA STI Database, the largest collection of aeronautical and space science STI in the world. The Program Office is also NASA's institutional mechanism for disseminating the results of its research and development activities. These results are published by NASA in the NASA STI Report Series, which includes the following report types:

- $\quad$ TECHNICAL PUBLICATION. Reports of completed research or a major significant phase of research that present the results of NASA programs and include extensive data or theoretical analysis. Includes compilations of significant scientific and technical data and information deemed to be of continuing reference value. NASA's counterpart of peerreviewed formal professional papers but has less stringent limitations on manuscript length and extent of graphic presentations.

- TECHNICAL MEMORANDUM. Scientific and technical findings that are preliminary or of specialized interest, e.g., quick release reports, working papers, and bibliographies that contain minimal annotation. Does not contain extensive analysis.

- CONTRACTOR REPORT. Scientific and technical findings by NASA-sponsored contractors and grantees.
- CONFERENCE PUBLICATION. Collected papers from scientific and technical conferences, symposia, seminars, or other meetings sponsored or cosponsored by NASA.

- SPECIAL PUBLICATION. Scientific, technical, or historical information from NASA programs, projects, and missions, often concerned with subjects having substantial public interest.

- TECHNICAL TRANSLATION. Englishlanguage translations of foreign scientific and technical material pertinent to NASA's mission.

Specialized services that complement the STI Program Office's diverse offerings include creating custom thesauri, building customized data bases, organizing and publishing research results ... even providing videos.

For more information about the NASA STI Program Office, see the following:

- Access the NASA STI Program Home Page at http://www.sti.nasa.gov

- E-mail your question via the Internet to help@sti.nasa.gov

- Fax your question to the NASA Access Help Desk at 301-621-0134

- Telephone the NASA Access Help Desk at 301-621-0390

- Write to:

NASA Access Help Desk

NASA Center for AeroSpace Information 7121 Standard Drive

Hanover, MD 21076 
NASA/TM-2001-210711

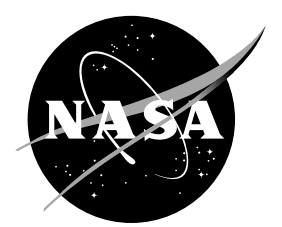

\section{Density Fluctuation in Asymmetric Nozzle Plumes and Correlation With Far Field Noise}

\section{J. Panda}

Ohio Aerospace Institute, Brook Park, Ohio

K.B.M.Q. Zaman

Glenn Research Center, Cleveland, Ohio

Prepared for the

39th Aerospace Sciences Meeting and Exhibit

sponsored by the American Institute of Aeronautics and Astronautics

Reno, Nevada, January, 8-11, 2001

National Aeronautics and

Space Administration

Glenn Research Center 


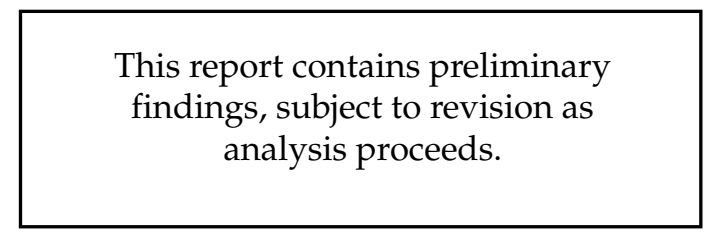

Available from

NASA Center for Aerospace Information

7121 Standard Drive

Hanover, MD 21076

Available electronically at http://gltrs.grc.nasa.gov/GLTRS 


\title{
Density Fluctuation in Asymmetric Nozzle Plumes and Correlation With Far Field Noise
}

\author{
J. Panda \\ Ohio Aerospace Institute \\ Cleveland, Ohio 44142 \\ K.B.M.Q. Zaman \\ National Aeronautics and Space Administration \\ Glenn Research Center \\ Cleveland, Ohio 44135
}

\begin{abstract}
A comparative experimental study of air density fluctuations in the unheated plumes of a circular, 4-tabbed-circular, chevron-circular and 10-lobed rectangular nozzles was performed at a fixed Mach number of 0.95 using a recently developed Rayleigh scattering based technique. ${ }^{1}$ Subsequently, the flow density fluctuations are cross-correlated with the far field sound pressure fluctuations to determine sources for acoustics emission. The nearly identical noise spectra from the baseline circular and the chevron nozzles are found to be in agreement with the similarity in spreading, turbulence fluctuations, and flow-sound correlations measured in the plumes. The lobed nozzle produced the least low frequency noise, in agreement with the weakest overall density fluctuations and flow-sound correlation. The tabbed nozzle took an intermediate position in the hierarchy of noise generation, intensity of turbulent fluctuation and flow-sound correlation. Some of the features in the 4-tabbed nozzle are found to be explainable in terms of splitting of the jet in a central large core and 4 side jetlets.
\end{abstract}

\section{INTRODUCTION}

The current study is a part of an ongoing effort to reduce jet noise from turbofan engines by nozzle contouring and by using mixing enhancement devices. In the past a large number of experimental studies have been conducted, first to look into the mixing improvement and, later on to determine the noise benefits of asymmetric configurations over the baseline axisymmetric geometry (see references 2-8 and the references cited therein). Usually, it is straightforward to quantify the mixing and noise improvements, for a new nozzle design, via measurements of increased mass flux and overall sound pressure level. The problem, however, lies in explaining the reason for the change and more importantly, in predicting such changes beforehand. The streamwise vorticity introduction through the use of tabs has been studied extensively by Zaman et al. ${ }^{9}$ among others. The axial and tangential pressure gradients upstream of a tab generate two counterrotating vortices (per tab) that persist for a long downstream distance and modify the jet plume. A lobed nozzle also introduces two axial vortices per lobe by literally introducing radial velocity components in opposite directions in the primary and co-flowing streams. ${ }^{4}$ It is believed that the axial vortices increase the strain field, the local gradient in fluid properties and the surface areas for mixing. Straight, unbent chevrons perhaps introduce small amount of streamwise vorticity when one of the streams is curving over the chevron surface. Nonetheless, the attraction of chevrons is due to relatively smaller thrust loss compared to the other methods.

The problem becomes far more involved when it comes to explain the change in acoustics field from plumes of contoured nozzles. An increase in jet mixing does not necessarily cause a decrease in the noise emission. In many instances, an increase in mixing leads to a decrease in the low frequency noise emission but leads to an increase in the high frequency part $^{8}$. The fundamental difficulty in noise study lies with our inability to determine its sources inside the turbulent plume. Theoretically there is no universally 
accepted formulation of noise source. The noise source terms in classical Lighthill's ${ }^{10}$ and Lilley's ${ }^{11}$ acoustic analogy approach have been criticized to combine acoustic propagation effects. ${ }^{12}$ The instability wave based approach of Morris and $\mathrm{Tam}^{13}$ and Tam and Burton ${ }^{14}$ is primarily applicable for supersonic Mach number conditions and is unsuccessful in predicting subsonic jet noise. Computationally Direct Numerical Simulation makes jet noise calculations from the first principle possible, yet only for very low Reynolds number condition. A useful computational tool to predict noise from asymmetric, practical Reynolds number jet is yet to come.

Experimentally the problem of source identification is two folded. First, a reliable tool to measure unsteady turbulence in compressible flow is unavailable. Second, even if such a tool is available, it is difficult to determine that the measured flow fluctuation is truly creating far field acoustic radiation. The commonly used microphone phased array tries to avoid these problems by simply using far field microphones to trace back to the ray origin. The method is indirect and relies on a priori estimate and assumed monopole nature of the source. Some of the nozzles used for the present program were studied earlier by Zaman and Tam ${ }^{15}$ and Tam and Zaman ${ }^{16}$ to establish noise emission characteristics. Zaman and $\mathrm{Tam}^{15}$ inserted a hot wire in the Mach 0.93 jet and faced expected problems of intrusiveness, ambiguity in signal interpretation, frequent breakage and spurious oscillations. Recently, a molecular Rayleigh scattering based technique, suitable for unsteady density measurements, has been developed by Panda and Seasholtz ${ }^{1,17}$ and has been used to make a comparative study of axisymmetric plumes at different Mach number conditions. In the present work the same technique is applied to compare changes in density fluctuations spectra in the asymmetric nozzle plumes. The problem of sound source location is addressed through a direct correlation study "between the cause and the effect (Lee and Ribner ${ }^{18}$ )", that is, between the turbulent density fluctuations and far field noise. For this purpose the air density fluctuations at a given point in the jet was measured using the Rayleigh scattering technique, and simultaneously the far field sound pressure fluctuations were measured using a microphone. A cross-correlation between the two signals provides a means of determining sound source. The goal of the present work is to make a comparative study of the turbulence field and flow-density to far-field-sound-pressure correlation for different asymmetric nozzle configurations. It follows the promise of Zaman and Tam: ${ }^{15}$ "Further investigation of the turbulence spectra, by non-obtrusive measurement technique, and correlation with far field noise are planned for the future."

\section{EXPERIMENTAL SETUP}

The experiments were performed in a small jet facility at the NASA Glenn Research Center. The nozzle exit geometries are shown in Fig. 1. All nozzles had a nominal equivalent diameter $\mathrm{D}=$ $2.54 \mathrm{~cm}$. Blockage from the 4 "delta-tabs" in the tabbed-nozzle caused a small reduction in the equivalent area. Unlike the axisymmetric configuration, a single length scale is insufficient to describe asymmetric configurations. The penetration distance of tabbed nozzle is expected to influence the upstream pressure gradient and thereby, the strength of the streamwise vortices. For a lobed nozzle the details of the convergent section and circular to lobe transition is expected to determine the magnitude of radial velocity and thereby, the strength of axial vortices. The present lobed nozzle was contoured from an initial $38 \mathrm{~mm}$ diameter circular inlet. Another parameter is the passage width $(4.43 \mathrm{~mm}$ for the present case) that determines viscous losses through Reynolds number effect. The chevron nozzle had six $90^{\circ}$ chevrons; each was straight, i.e., parallel to the exit flow. All unheated plumes were produced at the nominally fixed operating condition shown in Table I.

\section{Table I. Operating conditions.}

\begin{tabular}{|c|c|}
\hline \multicolumn{2}{|c|}{$\begin{array}{l}\text { Sp. heat ratio, } \gamma=1.4 \\
\text { Total temp. } \mathrm{T}_{0}=300^{\circ} \mathrm{K} \\
\text { Ambient density, } \rho_{\mathrm{a}}=1.16 \mathrm{Kg} / \mathrm{m}^{3} \text {, }\end{array}$} \\
\hline Operating Mach number $\mathrm{M}=$ & 0.95 \\
\hline Reynolds number $\operatorname{Re}_{\mathrm{D}}$ & $0.66 \times 10^{6}$ \\
\hline Jet Velocity $U_{j}(\mathrm{~m} / \mathrm{s})$ & 316 \\
\hline Jet density $\rho_{\mathrm{j}}\left(\mathrm{kg} / \mathrm{m}^{3}\right)$ & 1.36 \\
\hline Difference $\left(\rho_{\mathrm{j}}-\rho_{\mathrm{a}}\right)\left(\mathrm{kg} / \mathrm{m}^{3}\right)$ & 0.2 \\
\hline Frequency $(\mathrm{kHz})$ for $\mathrm{Sr}=1$ & 12.4 \\
\hline
\end{tabular}

The point measurement technique using Rayleigh scattering principles has been described in details in references 1 and 17. The current optical arrangement around the jet facility, shown in Fig. 2, provides improvements of increased laser power and accessibility to the flow region right out of nozzle exit compared to the earlier setup. In brief, a polarized, narrow laser beam from a continuous wave, frequency doubled $\mathrm{Nd}: \mathrm{VO}_{4}$ laser $(532 \mathrm{~nm}$ wavelength) was passed perpendicular to the jet axis. The light scattered by the air molecules were collected 
vertically below, at $90^{\circ}$ from the incident light direction. The f/\# 3.3 collection lenses focused the scattered light on the face of a $0.55 \mathrm{~mm}$ diameter receiving optical fiber. The fiber diameter and the magnification ratio of the collection optics fixed the probe volume length to $1.06 \mathrm{~mm}$. The beam waist was about $0.16 \mathrm{~mm}^{2}$ in cross-section. In effect, light scattered from this small length of the beam was collected by the receiving fiber. The collected light was then split into two parts and measured using a pair of photo multiplier tubes (PMT) and photon counting electronics (not shown in Fig. 2). This latter part is identical to the description of reference 1. Both the laser source and the receiving optics were placed on a X-Y traverse that allowed the probe volume to be moved from point to point in the jet plume. An important concern in Rayleigh scattering setup is dust removal from air streams, since laser light scattering from the naturally present dust particles is a few orders of magnitudes higher than the molecular scattered light. In the present setup the primary air was cleaned using air filters that blocked particles above a micron diameter. In addition, an 8 " diameter low speed co-flow around the primary jet was maintained using a second filtered air source to avoid particles through the entrained air.

Fundamentally, for a constant molecular composition air and a fixed optical system, the intensity of scattered light was directly proportional to the local air density $\rho$. Since light intensity is measured in terms of number of photoelectrons $\mathrm{N}$ counted over a given time interval $\Delta \mathrm{t}$, the following relationship holds

$$
N=(a \rho+b) \Delta t \text {. }
$$

Here $\mathrm{a}$ and $\mathrm{b}$ are constants determined through an in situ calibration. The calibration process was the first step in density measurement. It was performed in the plume of the baseline circular convergent nozzle operated in the Mach number range of 0 to 0.99 . At each operating condition the photon arrival rate was counted over a second duration and the jet density is calculated using isentropic relations. Subsequently, a straight line was fitted through the data to determine the proportionality constants a and b. Since two PMT and photoelectron counters were used, two sets of calibration constants $a_{1}, b_{1}$ and $a_{2}, b_{2}$ were calculated. The photoelectron counting was performed over a series of contiguous time bins. The statistical mean and mean-square of the counts, when multiplied by the calibration constants, provided corresponding statistics in terms of air density.
The 2 PMT technique was necessary to measure fluctuation spectrum. A simpler approach would be to use a single PMT, perform a single series of photon counting, and to take a Fourier transform of the series. That method, however, is seriously affected by electronic shot noise inherent in any optical measurements. To reduce the effect of shot noise, the collected Rayleigh scattered light was split into two parts, measured using two PMTs and photon counting electronics and finally the two series of photon counts were cross-correlated. Since, shot noise emitted by individual PMT are uncorrelated, contribution from this source is significantly reduced. In fact, for the present unheated jets, where density fluctuations are relatively small, no spectral information can be obtained without this two PMT process. Reference 1 further explains the technique.

The flow-sound cross correlation was measured by simultaneously measuring sound pressure fluctuations using a $1 / 4$ inch microphone and flow density fluctuations through Rayleigh scattered light. The microphone was kept fixed at a far field point and the laser probe volume was moved from point to point in the flow. For all data presented in this paper the microphone was kept at the peak noise emission angle of $30^{\circ}$ to the flow direction and at a radius of 50 nozzle exit diameters. The microphone signal and the Rayleigh scattered light were measured simultaneously using, respectively, an analog-to-digital converter and photon counting electronics. An external timer signal was used to synchronize the acquisition processes. The crosscorrelation-density function $\mathrm{P}_{\rho^{\prime} \mathrm{p}^{\prime}}$, at various frequencies $\mathrm{f}_{\mathrm{l}}$, was calculated using the sequence of photon counts $\mathrm{N}_{\mathrm{i}}^{\prime}$ and digitized microphone signal $\mathrm{p}_{\mathrm{i}}^{\prime}$ :

$$
\begin{aligned}
& P_{N_{1}^{\prime} p^{\prime}}\left(f_{l}\right)=\frac{2}{n^{2}}\left(F_{N_{1}^{\prime}}\left(f_{l}\right) \cdot F_{p^{\prime}}^{*}\left(f_{l}\right)\right) \\
& P_{\rho^{\prime} p^{\prime}}\left(f_{l}\right)=\frac{P_{N_{1}^{\prime} p^{\prime}}\left(f_{l}\right)}{a \Delta t}
\end{aligned}
$$

Here $\mathrm{F}$ represents a Fourier transform. The crossspectral density has real and imaginary parts,

$$
P_{\rho^{\prime} p^{\prime}}(f)=\operatorname{Re} P_{\rho^{\prime} p^{\prime}}(f)-i \operatorname{Im} P_{\rho^{\prime} p^{\prime}}(f),
$$

which are used to determine the magnitude and coherence function.

$$
\left|P_{\rho^{\prime} p^{\prime}}\left(f_{l}\right)\right|=\sqrt{\operatorname{Re}^{2} P_{\rho^{\prime} p^{\prime}}\left(f_{l}\right)+\operatorname{Im}^{2} P_{\rho^{\prime} p^{\prime}}\left(f_{l}\right)}
$$




$$
\Gamma_{\rho^{\prime} p^{\prime}}^{2}\left(f_{l}\right)=\frac{\left|P_{N_{1}^{\prime} p^{\prime}}\left(f_{l}\right)\right|^{2}}{P_{N_{1}^{\prime} N_{1}^{\prime}}\left(f_{l}\right) P_{p^{\prime} p^{\prime}}\left(f_{l}\right)}
$$

The coherence function $\Gamma$ is used throughout the paper as a measure of correlation. Since the collected light was split and measured with two counters, the crosscorrelation was performed two times: between microphone signal and either one of the two series of counts. Finally, an average of the two results was calculated. The cross-correlation minimizes shot noise in the photon count data, but a noise floor persists. To lower the noise floor more than half a million $(524,288)$ data points were collected for each data string. The Fourier transform used the segmenting and averaging process.

\section{RESULTS AND DISCUSSION}

\section{A. Noise spectra and time averaged data:}

Figure 3 presents a comparison of sound pressure fluctuations between the baseline circular and all other geometries. Frequency f, in abscissa is nondimensionalized to Strouhal no. $\mathrm{Sr}=\mathrm{fD} / \mathrm{U}$, where $\mathrm{U}$ is the jet exhaust velocity. The microphone data are affected by unavoidable large optical components placed around the jet. A telltale sign of reflection is the ripples superimposed on the spectra. Nonetheless a comparison shows that the noise spectrum from the chevron jet is nearly identical to that from the baseline circular geometry. The lobed nozzle produced the most reduction in the lower, $\mathrm{Sr}<1.0$, end in expense of the largest increase in the higher end. The tabbed nozzle showed some reduction in the lower frequency side without a significant rise in the high frequency end. Figure 3 is used as a guide throughout the paper to look for similarity in trends in other measured parameters.

As a prelude to flow data some important aspects of viewing a jet flow through air density should be discussed. In a low speed unheated air jet, the density variations are negligibly small. As the jet velocity is increased (or if heated) the density difference between the ambient air and the jet core increases. For the present unheated case increasing Mach number causes an increase in cooling which, in turn, increases the density of the primary air jet. The turbulent density fluctuations are caused by simple mixing between the ambient and primary jet fluid, as well as by the inertial effects (local acceleration and deceleration) of flow. The former perhaps contributes more to the total fluctuations; although, the inertial effects are expected to be the source of acoustic radiation. Table I shows the density difference $\left(\rho_{\mathrm{j}}-\rho_{\mathrm{a}}\right)$ in the current experimental condition is 0.2 . Here $\rho_{\mathrm{j}}$ is the jet core density calculated from isentropic relations and $\rho_{a}$ is the ambient density. The accuracy of the current technique improves as this difference increases. The experimental data are nondimensionalized by the difference, $\left(\rho_{\mathrm{j}}-\rho_{\mathrm{a}}\right)$. The timeaveraged data $(\bar{\rho})$ are non-dimensionalized as $\left(\bar{\rho}-\rho_{\mathrm{a}}\right) /\left(\rho_{\mathrm{j}}-\rho_{\mathrm{a}}\right)$. The parameter is unity at core and drops to 0 as the ambient condition is reached. The fluctuating density data are also normalized by $\left(\rho_{\mathrm{j}}-\rho_{\mathrm{a}}\right)$, i.e., $\rho_{\mathrm{rms}} /\left(\rho_{\mathrm{j}}-\right.$ $\left.\rho_{\mathrm{a}}\right)$. Note that the normalization process increases the relative uncertainty. For example, the uncertainty in the absolute measurement of time-averaged density is $\pm 1 \%$. This manifests as an error of $\pm 5 \%$ in the nondimensionalized presentation of data.

Figure 4 shows the centerline behavior of mean density and root-mean-square turbulent fluctuations for all of the nozzle configurations. The relative uncertainty in the time mean data is about $\pm 5 \%$ and that in the root-mean-square data is about $\pm 10 \%$. The latter also has a bias error of maximum 10\%. Figure 4(a) shows that: (1) the circular and chevron nozzles have similar centerline decay characteristics; (2) the tabbed nozzle causes the fastest decay of the centerline density and (3) the lobed nozzle has the slowest over the measurement distance of 12D. Close to the nozzle exit, the higher density values for tabbed and lobed nozzles may be associated with the flow acceleration caused by the streamwise vortices. Data from the lobed nozzle show two different slopes of decay: a faster rate close to nozzle exit $0 \leq \mathrm{x} / \mathrm{D} \leq 2$, and a slower rate thereafter. The former is associated with merging of shear layer across the channel width and the latter with spreading of overall plume. The root-mean-square density fluctuations of Fig. 4(b) shows a slow growth till the end of potential core, around $\mathrm{x} / \mathrm{D}=8$, for the circular, lobed and chevron geometries. While for the tabbed geometry, the peak occurs around $\mathrm{x} / \mathrm{D}=4$. Another observation from this figure is that the peak value of fluctuations from the lobbed nozzle is somewhat lower $(\sim 15 \%)$ than that measured in all other configurations $(\sim 20 \%)$.

In some instances the centerline decay characteristics of asymmetric nozzles is insufficient to determine the changes in jet spreading. Therefore, radial profiles were surveyed from a few downstream locations. Such profiles are shown in Fig. 5. Note that the radial directions where the surveys were conducted are shown in Fig. 1. Once again the circular and chevron nozzles have nearly similar radial profiles. The profile at $\mathrm{x} / \mathrm{D}=10$ from lobed nozzle tend to indicate a relatively higher mass flux through the core region and the associated weaker radial 
spreading (cause for the slower decay in centerline density). The profiles from the tabbed nozzle show the maximum spread; an explanation of which lies in the radial plane used for the survey. Based on the earlier flow visualization photographs ${ }^{9}$ distortions caused by the four tabs are sketched in Fig. 6. The measurement plane lies in the finger like protrusions that cause maximum radial throw of jet fluid. Additional data in a plane containing tabs would have provided supporting evidences. Another feature of the tabbed jet is the side shoulders seen at $x / D=2$. The shoulders indicate that the jet is split into a central large core and 4 side jetlets.

\section{B. Density fluctuation spectra}

The two PMT cross correlation technique significantly reduces electronic shot noise contribution, although, like any other spectral measurement, a residual level persists. An estimate of this residual level was obtained from data obtained at 'no-flow' condition. ${ }^{1}$ All spectra shown in Fig. 7 are found to be above this residual level. In addition to the noise base, the density spectra have a random uncertainty, the extent of which is visible in the randomness superimposed on the basic spectral shape. Figure 7 shows density fluctuation spectra measured along the lip shear layer of the circular jet. The data show a gradual shift in the spectral peak from $\mathrm{Sr}=1.3$ to 0.2 with an increase in the downstream distance. The trend follows velocity fluctuation measurements in low speed jets and expectations from hydrodynamic stability analysis. The latter establishes that an increase in shear layer thickness with downstream distance leads to an increased amplification of progressively longer wavelength and lower frequency Kelvin-Helmholtz instability waves.

To comprehend differences in the turbulent plume produced from different nozzles a large number of density spectra (typically 8 in $\mathrm{y} \mathrm{X} 8$ in $\mathrm{x}$ ) were measured in each plume. The spectral energy at given Strouhal frequencies was isolated and plotted in Fig. 8. There are 6 Strouhal frequency $(\mathrm{Sr}=2 ., 1.5$, $1.0,0.5,0.25$, and 0.12) plots for each nozzle configuration. The green shade in the color plot corresponds close to the noise floor and the yellow shade shows maximum energy. First the baseline circular geometry of Fig. 8(a) is described. Following expectations from instability wave based description, the higher frequency $(\mathrm{Sr}=2.0,1.5)$ occurs at the lip shear layer closer to the nozzle exit. The strongest fluctuations are at $\mathrm{Sr}=0.25$ and appear at the end of the potential core (around $x / D=7$ and $y / D=0.3$ ). The lowest frequency fluctuation $(\mathrm{Sr}=0.12)$ peaks along centerline and further downstream $(x / D=9)$.
Compared to the baseline case the chevron nozzle has slightly higher, yet nearly similar, distribution of density fluctuations at all Strouhal number conditions. The lobed nozzle, Fig. 8(d), shows the lowest level of fluctuations, especially at higher Strouhal frequencies (Sr > 1.0). The tabbed nozzle (Fig. 8c), following indications obtained from earlier time averaged data shows most distortions with peak fluctuations at all Strouhal frequencies appearing much closer to the nozzle exit.

Since a change in the amplitude and distribution of density fluctuations may or may not translate directly into a change of the far field noise, identification of noise sources is required. This has been performed through the following correlation study between turbulent density fluctuations in the flow and sound pressure fluctuations appearing in the far field.

\section{Flow-sound correlation:}

The intermediate steps towards the calculation of cross-spectral density are illustrated in Fig. 9. Part (a) shows the sound pressure fluctuation spectrum in a dimensional form $\left(\mathrm{Pascal}^{2}\right)$. Part (b) shows the density spectrum measured using two PMTs. Part (c) presents the magnitude of the cross-spectral density function (equation 4a). Finally, part (d) shows the coherence function obtained by normalizing cross-spectral density by the microphone spectrum and the spectrum of a single PMT output. The coherence function $\Gamma$ provides a measure of linear dependency between the flow fluctuations and the sound fluctuations. All correlation data presented in the rest of the paper are in terms of $\Gamma$. A coherence of unity represents perfect correlation while zero implies no correlation. In reality, the zero coherence was never measured due to the presence of a basic noise floor (shown as a dotted line in Fig. 9d). Similar to the density spectra, the noise floor was determined from no-flow measurements: The jet was turned off and the microphone and the Rayleigh signals were collected and analyzed. In addition, the jaggedness superimposed on the underlying coherence is indicative of random uncertainty. When measured coherence at a given frequency is above the noise floor, it can be said that some part of density fluctuation at that frequency from the laser probe location is creating sound pressure fluctuations at the microphone location; in other words, the probe location is a sound source. An increase in coherence implies an in increase in the source strength. However, an additional factor, the spatial coherence of the density fluctuations itself needs to be considered; for a point measurement from a fluctuation with long 
coherence length effectively provides a measure over the entire length. A higher value of the flow-sound coherence may also imply that the density fluctuations have a longer correlation length. The present single point measurement technique was unable to determine the coherence length scale. In summary, a higher value of measured coherence function may be due to two reasons: (a) a more efficient sound source and (b) a longer correlation length of the density fluctuations.

Before proceeding towards a comparative study, the nature of the coherence function measured from the baseline circular nozzle is explored. Figure 10(a) shows that no correlation above the noise floor is measurable from density fluctuations present in the lip shear layer. Along the centerline (Fig. 10b) no correlation is measured till the end of the potential core is reached. Beyond $\mathrm{x} / \mathrm{D}=6$ density fluctuations in $0<\mathrm{Sr}<0.4$ range show significant correlation with the far field noise. The peak coherence is measured in the $\mathrm{x} / \mathrm{D}$ range of 9 to 11 . Significant coherence value is measured from the furthest downstream station of $\mathrm{x} / \mathrm{D}=15$. All of these show that in Mach 0.95 jet, the low frequency sound source lies beyond the end of the potential core and it extends many jet diameters there on. The radial traverse at $x / D=9$ (Fig. 10c) shows that the peak coherence is measured from the centerline and it progressively weakens to the noise floor within $\mathrm{r} / \mathrm{D}=0.6$. Note that in all of Fig. 10 coherence above the noise floor is never found for fluctuations occurring beyond $\mathrm{Sr}=0.4$. The experimental technique is unable to detect the sound sources above that frequency for Mach 0.95 jet. Reference 1 shows that for higher Mach number plumes a different scenario manifests and the measurable coherence can be found till $\mathrm{Sr}=1.5$.

At this point it is useful to point out that the present Rayleigh scattering based technique is incapable of measuring density fluctuations associated with acoustic waves. The density fluctuations from the acoustic waves are at least 4 orders of magnitude below that from the turbulent flow, and therefore, fall below the measurement noise floor. Sound generated from sources along the centerline has to propagate through the turbulent flow before emanating into the outside quiescent region. Since density fluctuations from this propagating part is too weak to be detected, the present technique only identifies the sound sources and excludes the propagating sound waves.

A comparative study among the 4 nozzle configurations is presented in Fig. 11. The coherence data are from various locations along the centerline of each nozzle. Note that the corresponding far field noise spectra are presented earlier in Fig. 3. Interestingly the trend in the lower Strouhal number part $(\mathrm{Sr}<1)$ of the noise spectra is in agreement with the coherence data. This is discussed in the following. A comparison between the baseline circular and the chevron data, Fig. 11(a) and (b), shows a similarity in the peak coherence value and the Sr range over which they rise above the noise floor. This distribution of the low frequency source is in agreement with the identical noise spectrum measured for these two cases. The narrowest $\mathrm{Sr}$ range for the coherence data is measured from the lobbed nozzle (Fig. 11d), which is quietest in the lower Strouhal frequencies. The area under each coherence plot is a measure of the net effectiveness of flow density fluctuations in creating sound pressure fluctuations. In this measure the sound sources are the weakest in lobbed nozzle. The coherence data from the tabbed nozzle, Fig. 11(c), is shown for axial stations closer to the nozzle exit as its potential core dissipates earlier than others. The overall trends are better than lobbed nozzle yet weaker than circular or chevron nozzle, indicating the appropriate middle position in the hierarchy of low frequency sound reduction.

An interesting double hump behavior in the coherence data from some stations $(x / D=3,4$ Fig. 11c) in the tabbed jet plume led to further radial surveys shown in Fig. 12. The coherence data from all radial stations at $\mathrm{x} / \mathrm{D}=3$ show the same double hump behavior indicating the existence of 2 distinct noise sources. It is conjectured that the two sources may be due to the splitting of the jet into a bigger core jet and 4 smaller jetlets outlined in Fig. 6. The lower frequency part may be attributed to the former and the higher frequency to the interactions from the later. Notably, Tam and Zaman ${ }^{16}$ has proposed a similar jetlet model to explain increased high frequency noise from tabbed nozzle.

\section{SUMMARY AND CONCLUSION}

The paper presents a comparative survey of the density field and noise source of a baseline circular, 4-tabbed circular, 6-chevron circular and 10-lobbed rectangular nozzles. All plumes were unheated, single-stream (no co-flow) and at a fixed Mach number of 0.95 . The full benefit of some of the nozzle configurations, such as lobed and chevron, are believed to be achievable only in the presence of a coflow due to the details of streamwise vorticity generation mechanism. Nevertheless, the study provides some fundamental insights into the turbulence field and noise sources through an application of a novel Rayleigh scattering based technique. The particle-free, non-intrusive, point measurement technique provided air density fluctuation through a measurement of laser light 
scattering by air molecules. The sound source identification was performed through a causelty technique $^{18}$ where flow density fluctuations were correlated with the far field sound pressure fluctuations. In the unheated Mach 0.95 plume the technique identified low frequency sources in the range $0 \leq \mathrm{Sr} \leq 0.4$. Also in this Strouhal number range noise sources from the baseline circular nozzle are found to lie beyond the end of the potential core and many diameters thereon.

Compared to the baseline circular jet, plume from the straight chevron nozzle did not show any significant change in spreading, distribution of turbulent fluctuations and flow-sound correlation. This explains nearly identical noise spectra measured for these two cases.

The four-tab nozzle was found to be quieter than the baseline case in the low frequency end $(\mathrm{Sr}<1$.$) . The flow field and correlation data were$ gathered in the plane of maximum spreading. A quicker dissipation of the potential core was found to be associated with a similar early growth and decay of turbulent density fluctuations at all Strouhal frequencies. Effective splitting of the jet into a larger core and 4 smaller jetlets was confirmed from radial profiles obtained around $x / D=2$. The flow-sound correlation data obtained from this region showed the presence of two humps with peaks around $\mathrm{Sr} \sim 0.1$ and $\mathrm{Sr} \sim 0.35$. The double hump indicates two different acoustics sources. It is conjectured that the core jet and interaction from side jetlets are sources of the lower and higher frequency peaks. Additional data from the minimum spreading plane would have been useful and will be acquired in the future.

The lobed nozzle was found to be the most effective in quieting the low frequency noise, yet produces the most increase in the high frequency end $(\mathrm{Sr}>2)$. The flow fluctuations appearing at the high frequency end could not be resolved effectively to address the trend. However, an insight into the low frequency was obtained in the present study. In general, it was found that the low frequency $(\mathrm{Sr}<1)$ fluctuations were reduced in the lobed nozzle plume compared to the baseline circular case. This was confirmed from both the spectral data and the overall rms level measurements. In addition, the significantly low coherence value in the flow-sound correlation measurement indicated a weakening of sound sources in this jet.

\section{References}

${ }^{1}$ Panda, J. and Seasholtz, R.G. "Investigation of Density Fluctuations in Supersonic Free Jets and Correlation with Generated Noise," AIAA 2000-2099, $6^{\text {th }}$ AIAA/CEAS Aeroacoustics conference, Hawaii, June 2000.

${ }^{2}$ Ahuja, A., Manes, J., and Massey, K. "An Evaluation of Various Concepts of Reducing Supersonic Jet Noise," AIAA paper 90-3982, 1990.

${ }^{3}$ Gutmark, E.J. and Grinstein, F.F. "Flow Control With Noncircular Jets," Annu. Rev. Fluid Mech. 30, pp. 239-272, 1999.

${ }^{4}$ Waitz, I.A., Qiu, Y.J., Manning, T.A., et al., "Enhanced Mixing with Streamwise Vorticity," Prog. Aerospace Sci., 33, pp. 323-351, 1997.

${ }^{5}$ Belovich, V.M. and Samimy, M. "Mixing Processes in a Coaxial Geometry With a Central Lobed MixerNozzle," AIAA J., 35 (5), pp. 838-841, May 1997.

${ }^{6}$ Paterson, R.W., "Turbofan Mixer Nozzle Flow Field-A Benchmark Experimental Study," J. of Engr. for Gas Turbine Power, 106, pp. 692-698, July 1984.

${ }^{7}$ Ramesh, R., Pradeep, S., Muruganandam, T.M., and Sujith, R.I., "Studies on Freejets From Nozzles for High-Speed Mixing Applications," Experiments in Fluids, 29, pp. 359-368, 2000.

${ }^{8}$ Rogers, C.B. and Parekh, D.E., "Mixing Enhancement by and Noise Characteristics of Streamwise Vortices in an Air Jet," AIAA J., 32, pp. 464-471, March 1994.

${ }^{9}$ Zaman, K.B.M.Q., Reeded, M.F., and Samimy, M., "Control of an Axisymmetric Jet Using Vortex Generators," Physics of Fluids, 6 (2), pp. 778-793, 1994.

${ }^{10}$ Lighthill, M.J., 1954, On Sound Generated Aerodynamically I. General Theory. Proc. Royal Soc., A221 564-587.

${ }^{11}$ Lilley, G.M., 1972, The Generation and Radiation of Supersonic Jet Noise IV. Theory of Turbulence Generated Noise. USAPL TR-72-53.

${ }^{12}$ Wells, V.I. and Renaut, R.A., "Computing Aerodynamically Generated Noise," Ann. Rev. Fluid Mech., 29, pp. 161-199, 1997.

${ }^{13}$ Morris, P.J. and Tam, C.K.W, "On the Radiation of Sound by the Instability Waves of a Compressible Axisymmetric Jet," In Mechanisms of Sound Generation in Flows (ed. E.A. Muller). Springer, 1979. 
${ }^{14}$ Tam, C.K.W. and Burton, D.E. "Sound Generated by Instability Waves of Supersonic Flows. Part 2. Axisymmetric Jets," J. Fluid Mech. 138 249-271, 1984.

${ }^{15}$ Zaman, K.B.M.Q. and Tam, C.K.W., "Flow and Noise Field of Subsonic Jets From Asymmetric Nozzles", AIAA paper 99-3583, 1999.

${ }^{16}$ Tam, C.K.W. and Zaman, K.B.M.Q., "Subsonic Jet Noise From Non-Axisymmetric and Tabbed Nozzles," AIAA J., 38 (4), 592-599, April 2000.

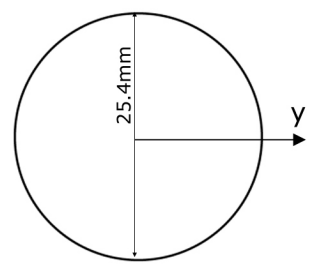

(a)

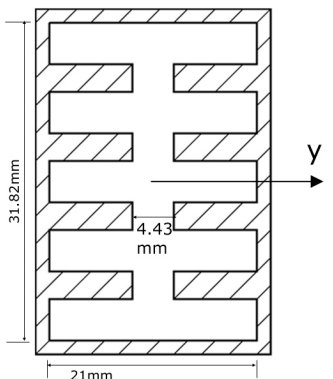

(c)

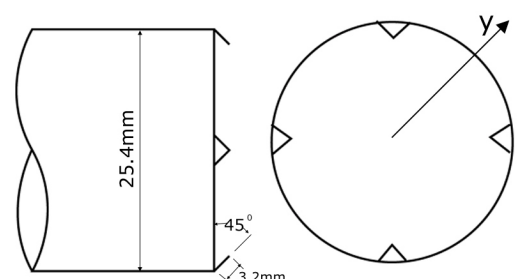

(b)

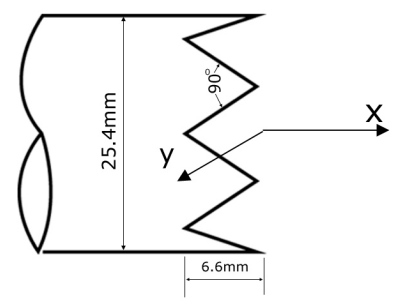

(d)
Fig. 1. Nozzle shapes used for this study; (a) Circular, (b) 4 - Tabbed Circular, (c) 10 - Lobed, (d) 6 straight chevron circular. All measurements were performed in $\mathrm{x}-\mathrm{y}$ plane: $\mathrm{x}$ is downstream direction and $\mathrm{y}$ is as shown.
${ }^{17}$ Panda, J. and Seasholtz, R.J., 1999c, Measurement of Shock Structure and Shock-Vortex Interaction in Underexpanded Jets Measured Using Rayleigh Scattering, Physics of Fluids, 11(12), 3761-3777.

${ }^{18}$ Lee, H.K. and Ribner, H.S., 1972, Direct Correlation of Noise and Flow of a Jet, J. Acoustic. Soc. of America. 52, no. 5 (pt. 1) 1280-1290.

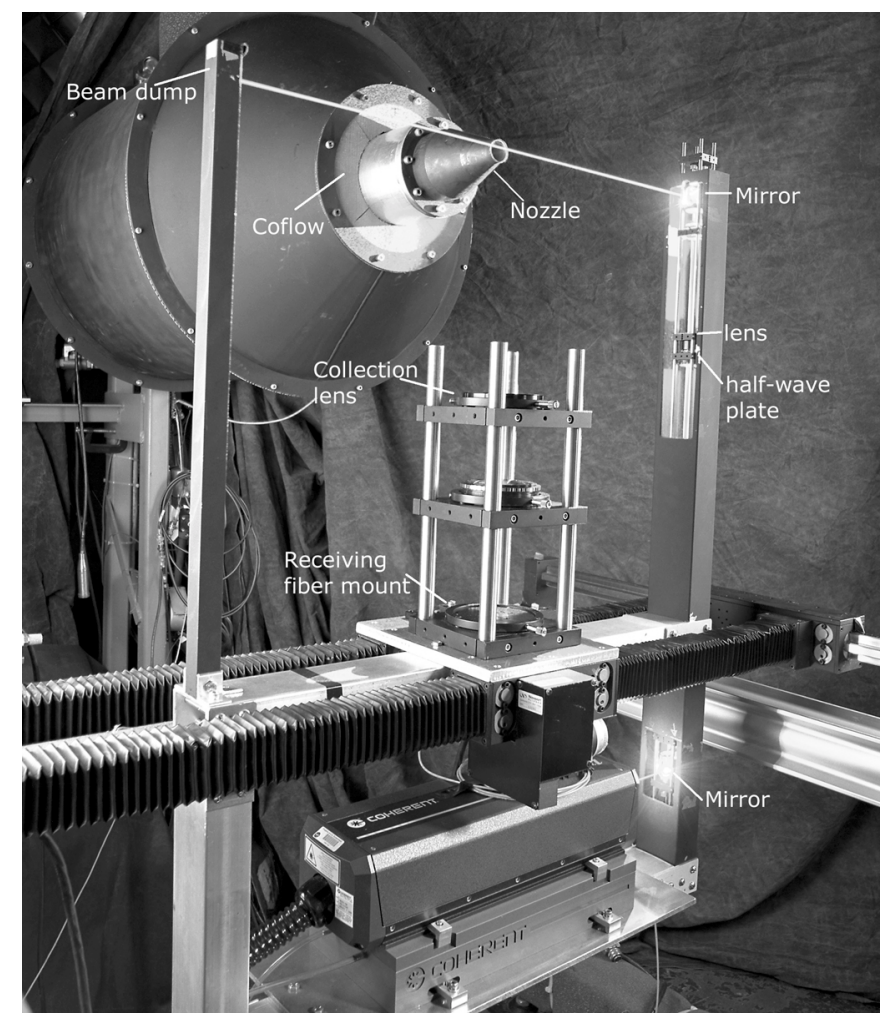

Fig. 2. Optical arrangement around the jet facility. 


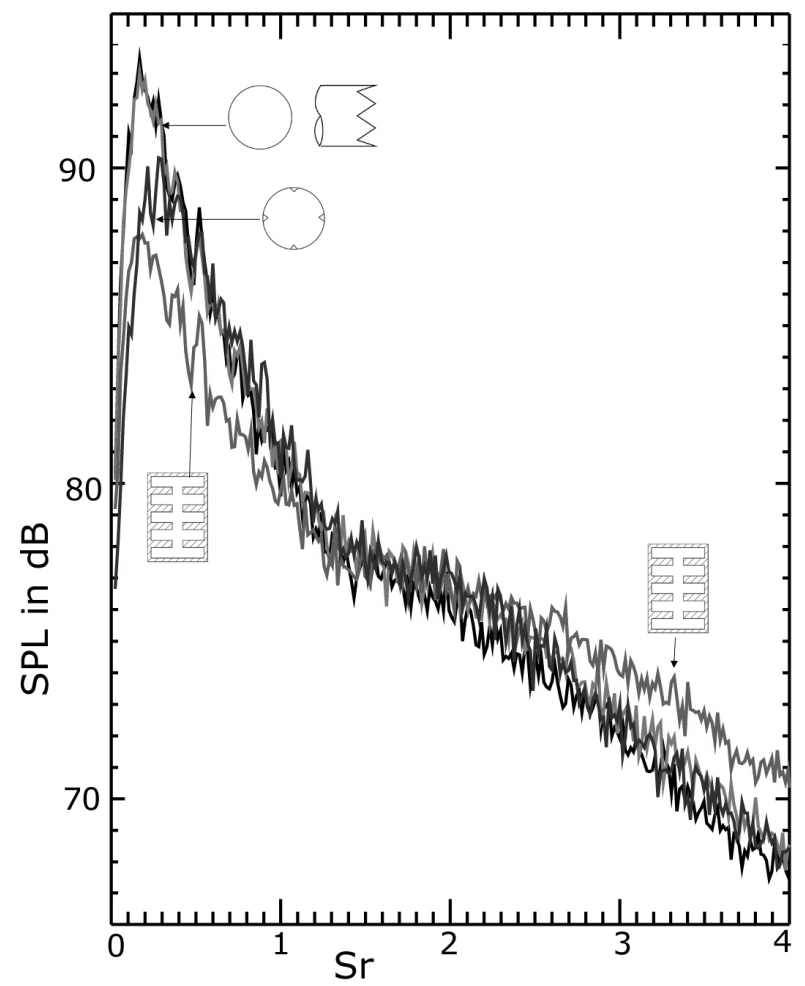

Fig. 3. Comparison of sound pressure level spectra for various nozzles. Microphone at 50D and $30^{\circ}$ from jet axis, $\mathrm{M}=0.95$.

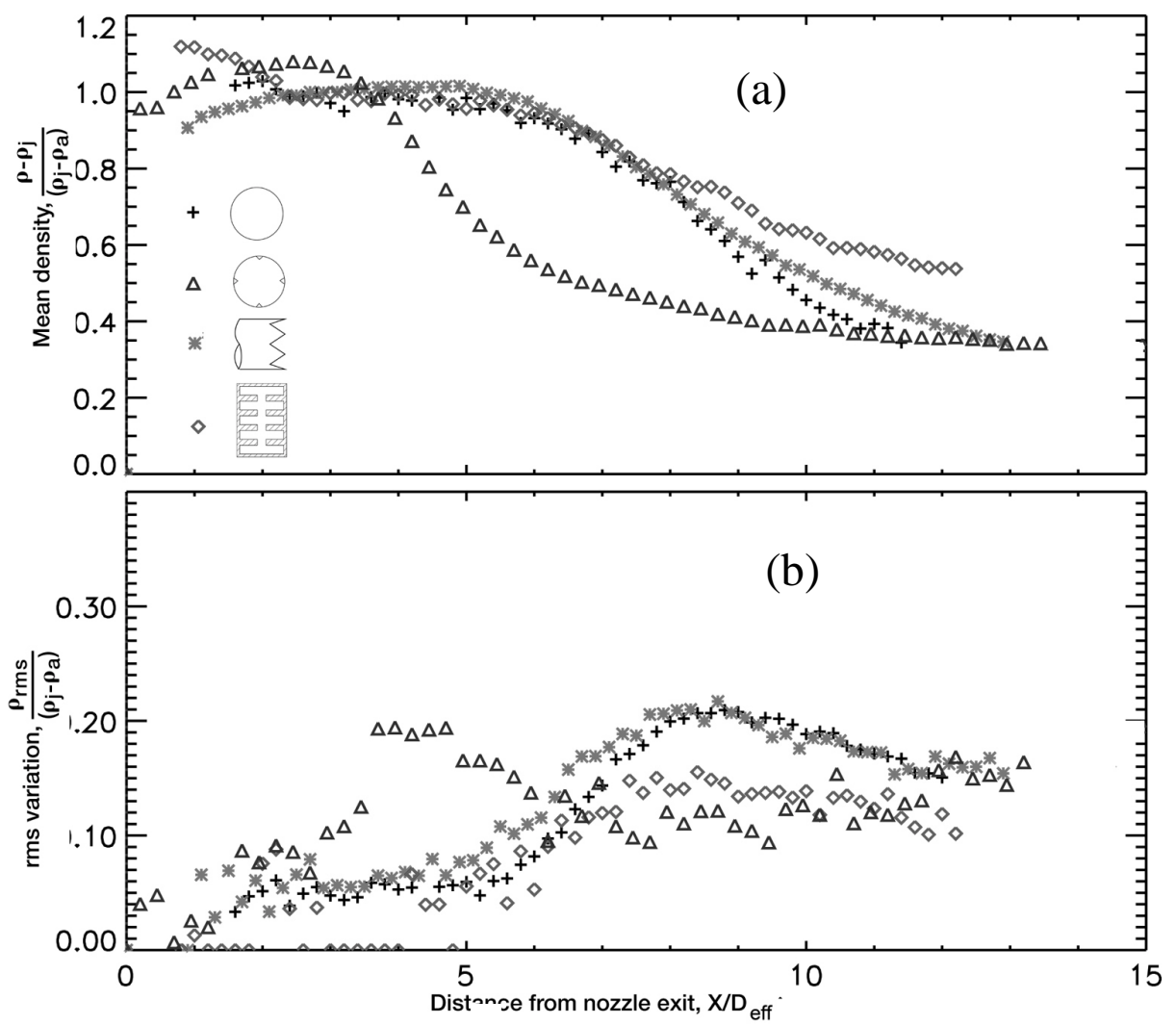

Fig. 4. Centerline decay of (a) mean density and (b) rms density fluctuations; $M=0.95$. 


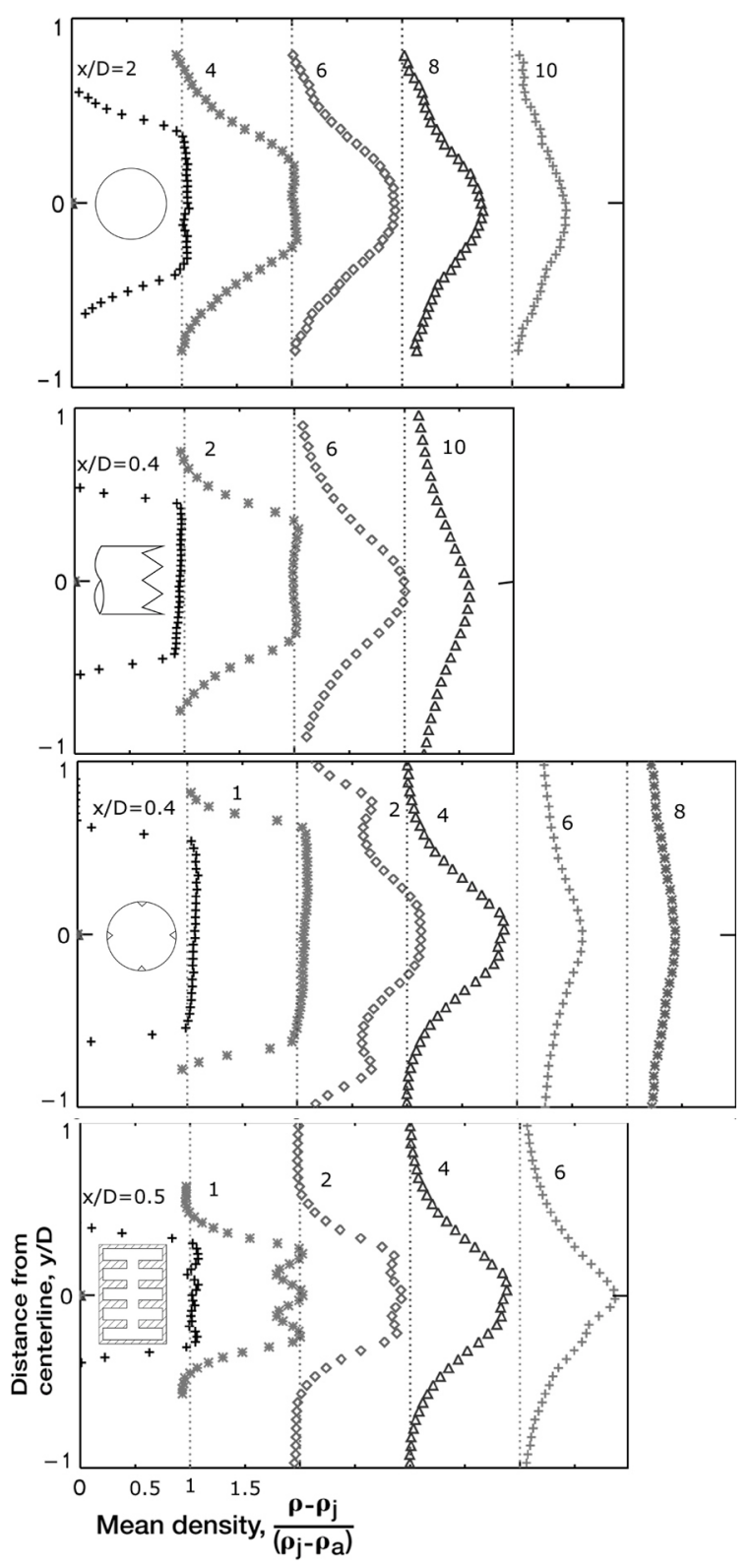

Fig. 5. Radial profiles of time-averaged density fluctuations from indicated nozzle configurations.

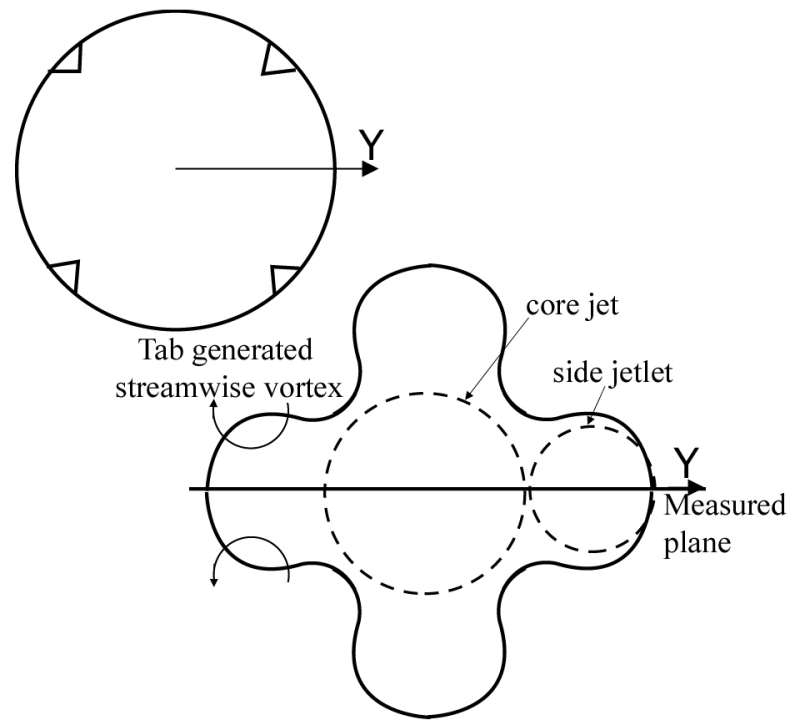

Fig. 6. Schematic of flow field from the 4-tabbed nozzle.

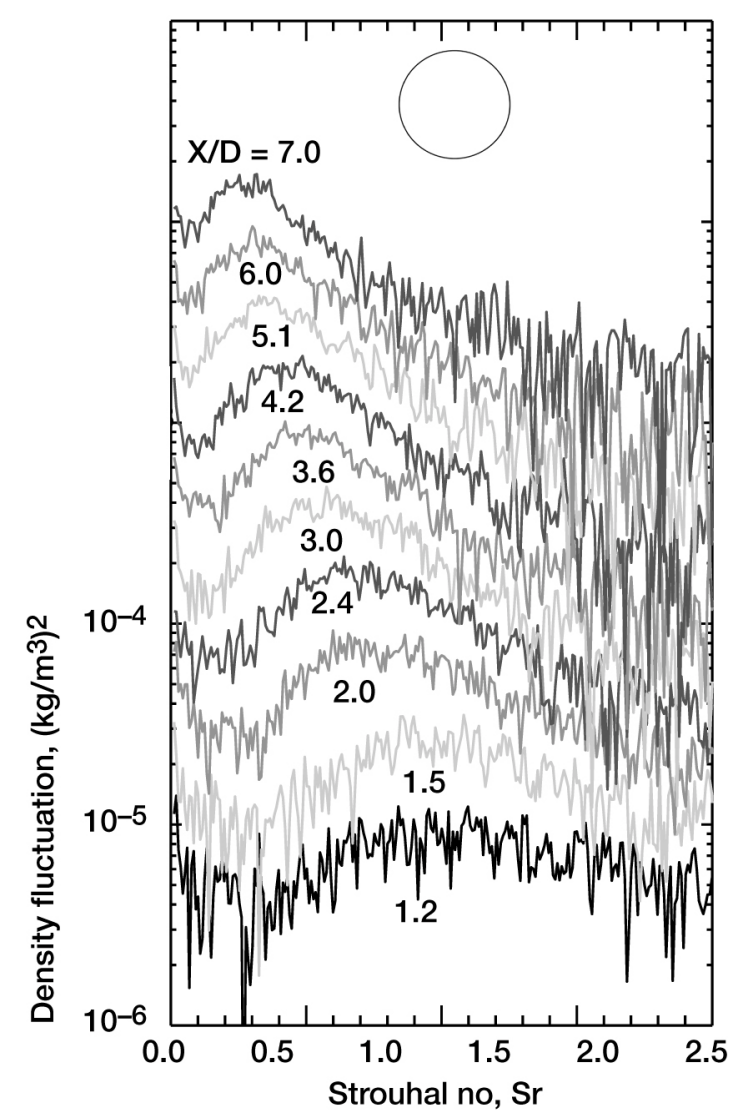

Fig. 7. Density fluctuation spectra from shear layer, $\mathrm{y} / \mathrm{D}=0.48$, at indicated axial position of baseline circular nozzle. 


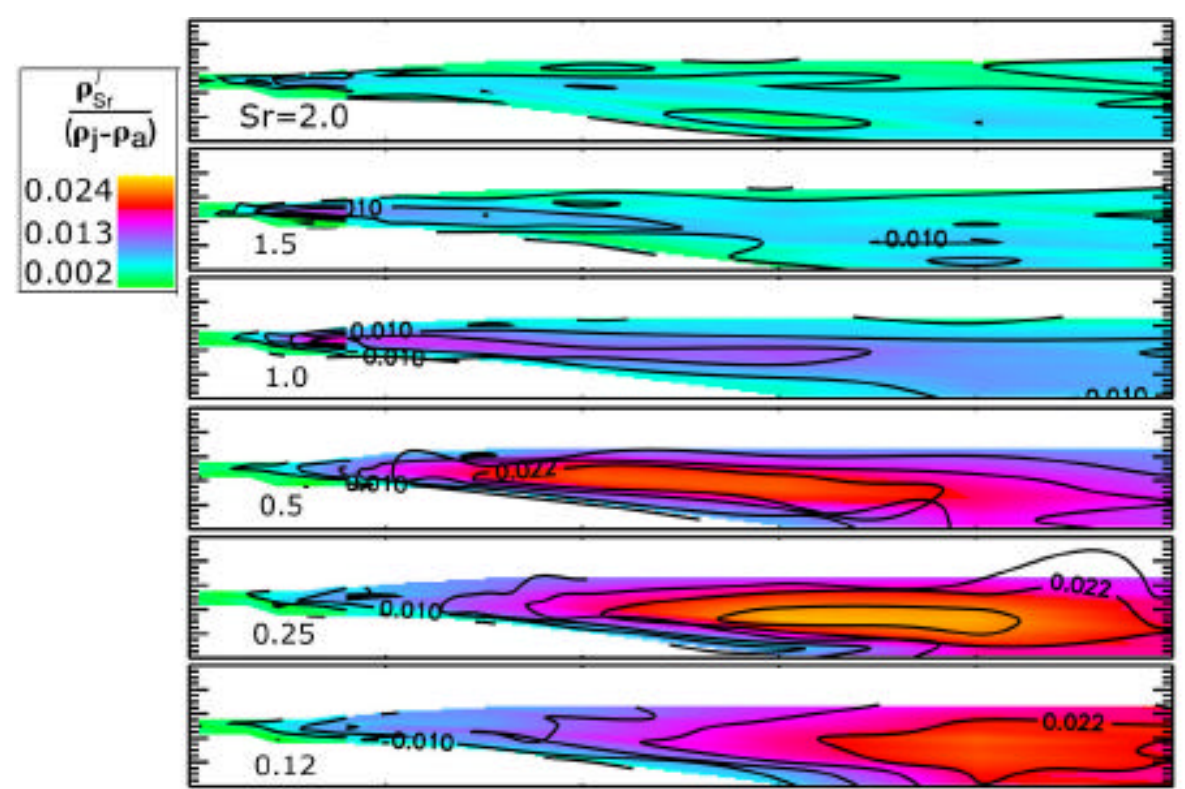

(a) Circular

$=$

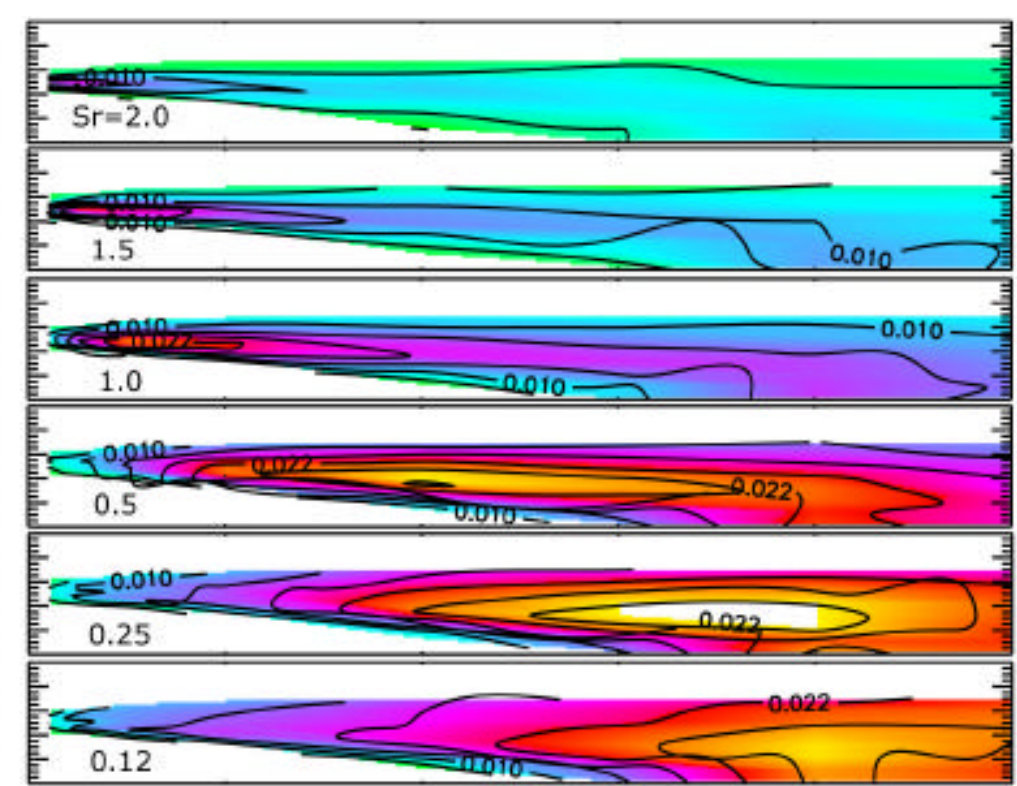

(b) Chevron

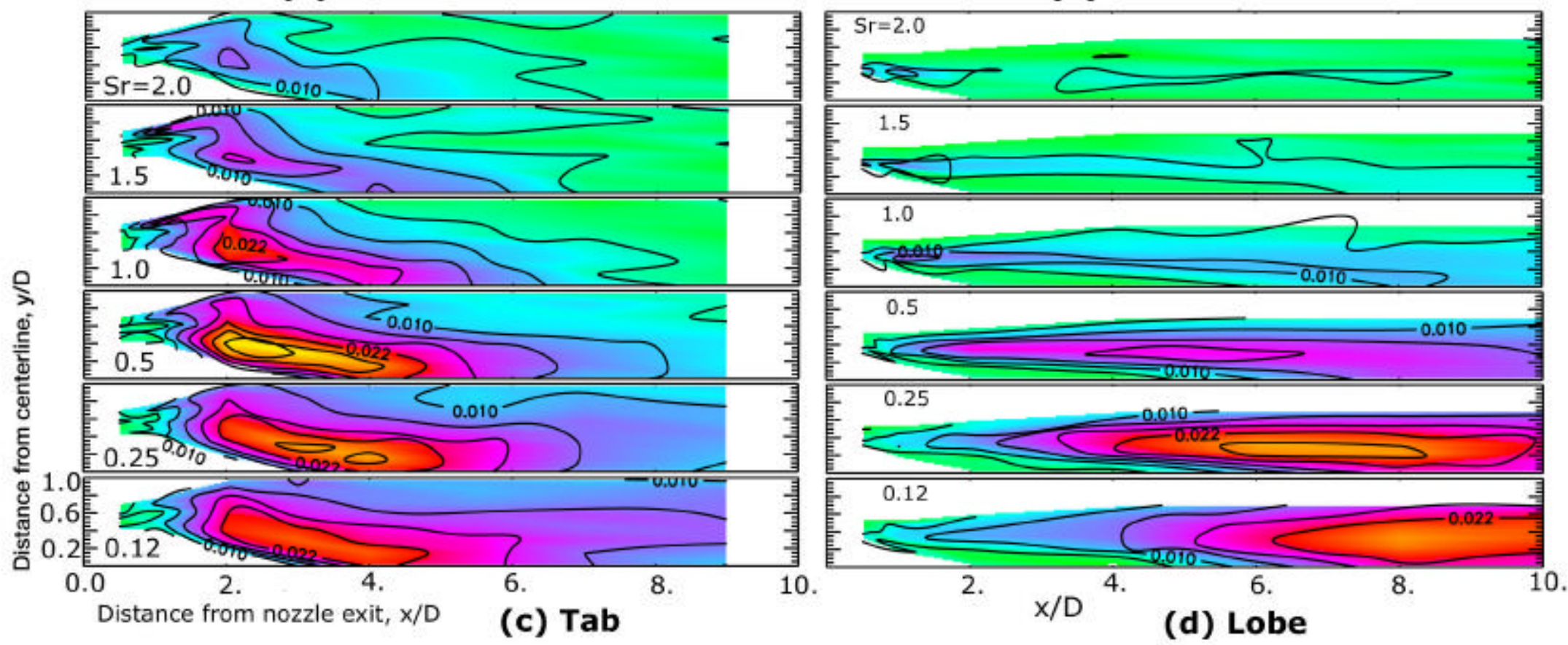

Fig. 8. Density fluctuations at indicated Strouhal frequencies for 4 nozzles. 

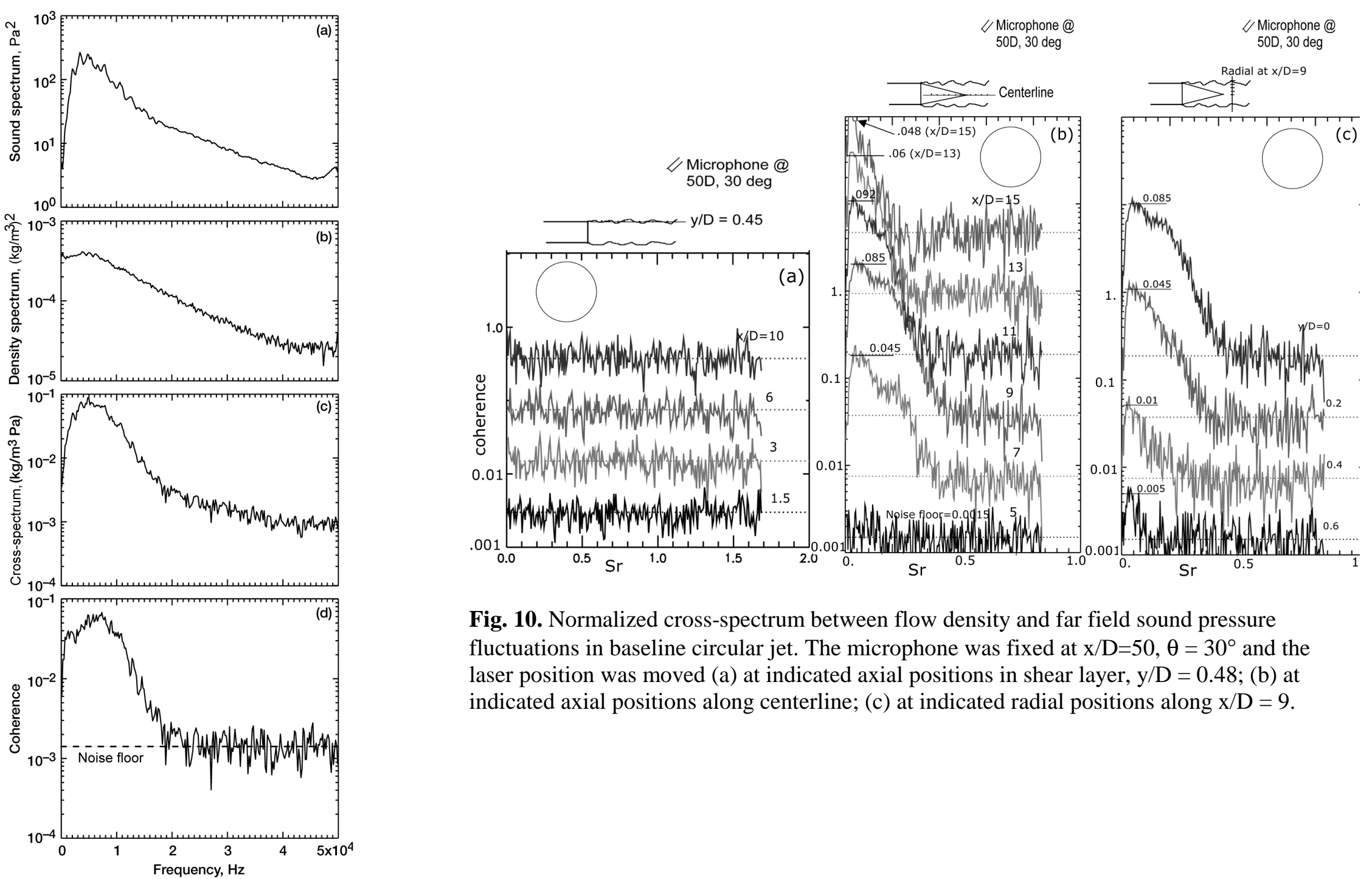

Fig. 10. Normalized cross-spectrum between flow density and far field sound pressure fluctuations in baseline circular jet. The microphone was fixed at $\mathrm{x} / \mathrm{D}=50, \theta=30^{\circ}$ and the laser position was moved (a) at indicated axial positions in shear layer, $y / D=0.48$; (b) at indicated axial positions along centerline; (c) at indicated radial positions along $\mathrm{x} / \mathrm{D}=9$.

Fig. 9. Cross-correlation between flow density fluctuations and sound pressure fluctuations in circular jet $(\mathrm{M}=1.8)$. Laser at centerline and $\mathrm{x} / \mathrm{D}=10$, microphone at far field $\mathrm{x} / \mathrm{D}=50, \theta=30^{\circ}$. (a) Sound pressure spectrum, (b) density spectrum, (c) cross-spectrum and (d) normalized crossspectrum (coherence). 


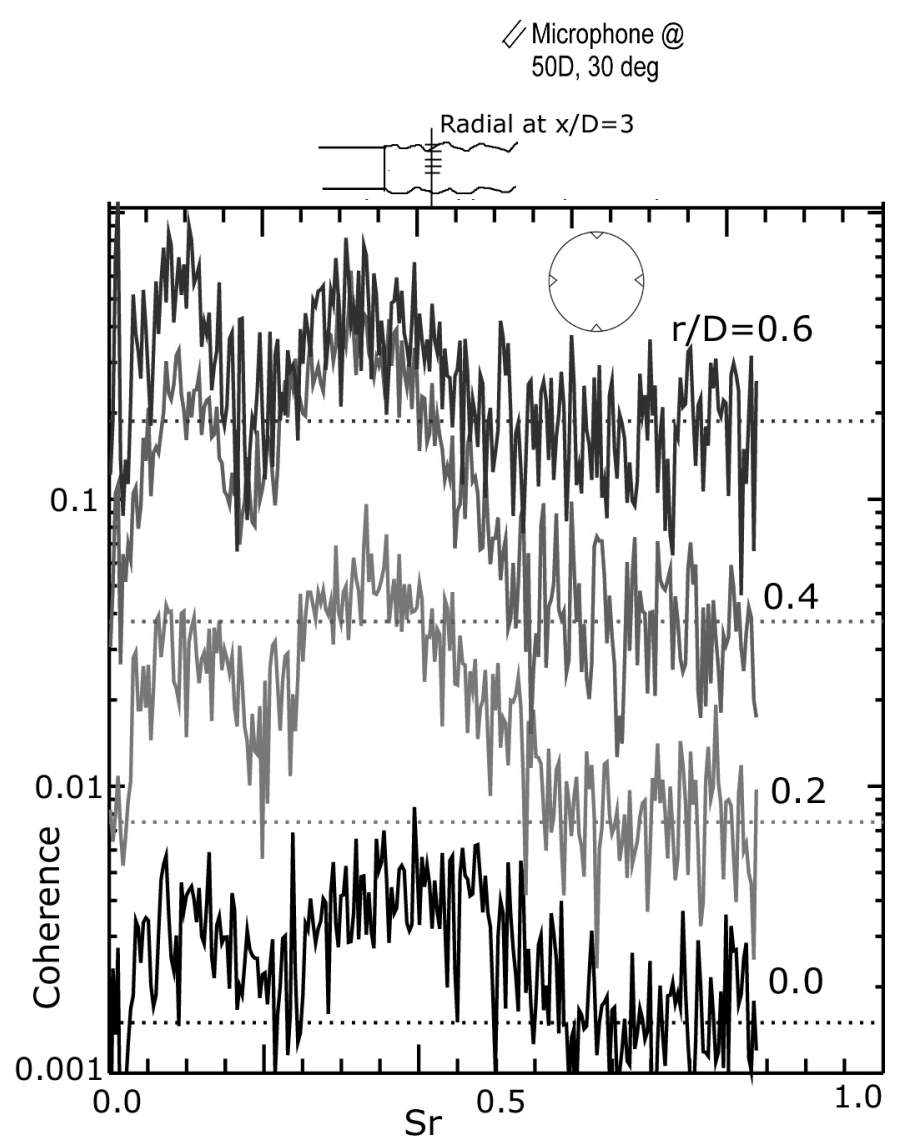

Fig. 12. Normalized cross-spectrum between flow density and far field sound pressure fluctuations in tabbed jet. The microphone was fixed at $\mathrm{x} / \mathrm{D}=50, \theta=30^{\circ}$ and the laser position was moved to indicated radial positions at $\mathrm{x} / \mathrm{D}=3$.

Fig. 11. A comparative study of normalized cross-spectrum between flow density and far field sound pressure fluctuations from the 4 different nozzle configurations. The microphone was fixed at $x / D=50, \theta=30^{\circ}$ and the laser position was moved at indicated axial positions along centerline. 
Public reporting burden for this collection of information is estimated to average 1 hour per response, including the time for reviewing instructions, searching existing data sources, gathering and maintaining the data needed, and completing and reviewing the collection of information. Send comments regarding this burden estimate or any other aspect of this collection of information, including suggestions for reducing this burden, to Washington Headquarters Services, Directorate for Information Operations and Reports, 1215 Jefferson Davis Highway, Suite 1204, Arlington, VA 22202-4302, and to the Office of Management and Budget, Paperwork Reduction Project (0704-0188), Washington, DC 20503.

\begin{tabular}{|l|l|l}
\hline 1. AGENCY USE ONLY (Leave blank) & $\begin{array}{c}\text { 2. REPORT DATE } \\
\text { May } 2001\end{array}$ & $\begin{array}{r}\text { 3. REPORT TYPE AND DATES COVERED } \\
\text { Technical Memorandum }\end{array}$ \\
\hline
\end{tabular}

4. TITLE AND SUBTITLE

5. FUNDING NUMBERS

Density Fluctuation in Asymmetric Nozzle Plumes and Correlation

With Far Field Noise

6. AUTHOR(S)

J. Panda and K.B.M.Q. Zaman

WU-704-20-53-00

\section{PERFORMING ORGANIZATION NAME(S) AND ADDRESS(ES)}

National Aeronautics and Space Administration

John H. Glenn Research Center at Lewis Field

Cleveland, Ohio 44135-3191

8. PERFORMING ORGANIZATION

REPORT NUMBER

E-12644

\section{SPONSORING/MONITORING AGENCY NAME(S) AND ADDRESS(ES)}

National Aeronautics and Space Administration

Washington, DC 20546-0001
10. SPONSORING/MONITORING AGENCY REPORT NUMBER

NASA TM-2001-210711

AIAA-2001-0378

\section{SUPPLEMENTARY NOTES}

Prepared for the 39th Aerospace Sciences Meeting and Exhibit sponsored by the American Institute of Aeronautics and Astronautics, Reno, Nevada, January, 8-11, 2001. J. Panda, Ohio Aerospace Institute, 22800 Cedar Point Road, Brook Park, Ohio 44142; and K.B.M.Q. Zaman, NASA Glenn Research Center. Responsible person,

K.B.M.Q. Zaman, organization code 5860, 216-433-5888.

12a. DISTRIBUTION/AVAILABILITY STATEMENT $\quad$ 12b. DISTRIBUTION CODE

Unclassified - Unlimited

Subject Categories: 34, 45 and 35

Distribution: Nonstandard

Available electronically at http://gltrs.grc.nasa.gov/GLTRS

This publication is available from the NASA Center for AeroSpace Information, 301-621-0390.

13. ABSTRACT (Maximum 200 words)

A comparative experimental study of air density fluctuations in the unheated plumes of a circular, 4-tabbed-circular, chevron-circular and 10-lobed rectangular nozzles was performed at a fixed Mach number of 0.95 using a recently developed Rayleigh scattering based technique. Subsequently, the flow density fluctuations are cross-correlated with the far field sound pressure fluctuations to determine sources for acoustics emission. The nearly identical noise spectra from the baseline circular and the chevron nozzles are found to be in agreement with the similarity in spreading, turbulence fluctuations, and flow-sound correlations measured in the plumes. The lobed nozzle produced the least low frequency noise, in agreement with the weakest overall density fluctuations and flow-sound correlation. The tabbed nozzle took an intermediate position in the hierarchy of noise generation, intensity of turbulent fluctuation and flow-sound correlation. Some of the features in the 4-tabbed nozzle are found to be explainable in terms of splitting of the jet in a central large core and 4 side jetlets.

\section{SUBJECT TERMS}

Jet noise; Turbulence; Rayleigh scattering

17. SECURITY CLASSIFICATION OF REPORT

Unclassified

\section{SECURITY CLASSIFICATION OF THIS PAGE \\ Unclassified}

19. SECURITY CLASSIFICATION OF ABSTRACT

Unclassified
15. NUMBER OF PAGES

18

16. PRICE CODE

20. LIMITATION OF ABSTRACT

Standard Form 298 (Rev. 2-89)

Prescribed by ANSI Std. Z39-18 298-102 